Collaborative product and service life cycle management for a sustainable world:

Proceedings of the 15th ISPE International Conference on Concurrent Engineering,

18-22 August 2008, Belfast, Northern Ireland, UK.

\title{
Cost of Physical Vehicle Crash Testing
}

\author{
Paul Baguley ${ }^{\mathrm{a} 1}$, Rajkumar Roy ${ }^{\mathrm{a}}$ and James Watson ${ }^{\mathrm{b}}$ \\ ${ }^{\text {a }}$ Decision Engineering Centre - Cranfield University, United Kingdom. \\ ${ }^{\mathrm{b}}$ Cranfield Impact Centre - Cranfield University, United Kingdom.
}

\begin{abstract}
The automotive safety-testing environment currently deploys virtual methods and physical crash testing for new product development and validation in safety testing legislation. Cost benefit analysis of crash testing is considered here by estimating the cost of physical crash testing. This has been achieved via the compilation of detailed process maps and AS-IS analyses of the current physical testing procedures. This leads on to detailed work and cost breakdown structures used in the comparative analysis of cost drivers. The consideration of cost drivers at several stages of the New Product Development process aids Concurrent Engineering. This research considers front and side impact only.
\end{abstract}

Keywords: Physical crash testing, cost estimating, cost of crash testing

\section{Introduction}

Crash testing, or the study of crashworthiness, is a method of measuring how well a vehicle withstands a crash or sudden impact. European legislation still requires physical testing for final safety analysis and legislation, but, due to the high number of iterations and repetitions involved in the overall testing procedure, from design to final approval, even a partial conversion to the virtual simulation testing domain could have large cost saving opportunities. It may also have implications on raising car safety standards by increased integrity and more complex parametric testing that wouldn't be possible in physical tests.

An investigation has taken place into the potential of introducing wider virtual impact testing within the vehicle development process, assessing the cost and benefits to legislation, society and car manufacturers. The study was undertaken via the formulation of detailed process maps, and cost breakdown structures. Data and information has been collected via communication with a number of external parties, including private car manufacturers, academics, public services and other interested parties, and these sources were also utilised in the final validation of outputs. This paper reports on the results of investigating physical crash testing only.

\footnotetext{
${ }^{1}$ Corresponding Author E-mail: p.baguley@cranfield.ac.uk
} 


\section{Aim and Objectives}

The aim of the research is to investigate the cost and benefit of the amount of virtual and crash testing. This is developed using cost estimates of physical crash testing. Front and side impact of physical crash testing is considered only. The objectives of the research are to:

- Identify cost breakdown structures for physical crash testing.

- Identify cost drivers and some of their behaviour physical crash testing.

- Validate the above using industry experts.

\section{Literature Background}

The process of physical crash testing has evolved dramatically since the first official test took place in 1969 , both as a result of increased societal emphasis on vehicle safety and the utilisation of new technology. It remains the primary measure of vehicle crashworthiness, and indeed the only compulsory method accounted for in official legislation.

By law, all new car models must pass certain safety tests before they are sold. These specific safety requisites vary worldwide and are defined by the legislation of the country in which the car is to be licensed. In the UK and other countries in the European Union, legislation controlling vehicle safety and crashworthiness is defined by ([1]) the United Nations Economic Commission for Europe (UNECE) Working Party of the Construction of Vehicles (WP29). This legislation largely evolved in complexity throughout the $20^{\text {th }}$ Century as road travel increased, in line with harsher controls on vehicle safety and the increasing introduction of safety features such as seatbelts and airbags.

Cost Engineering is a multi-disciplinary profession including estimating costs ([2]). For example the development of cost model equations for estimating costs of design from a dataset ([3]).

\section{Methodology}

Seven companies, three academics, two consultants, and 30 hours of interviews were used to collect qualitative and quantitative data about the structure and behaviour of costs of the three domains of virtual test, physical test and cost to society. Overall 56 experts were contacted via a questionnaire, however not all were able to take part.

The development of the domains other than that of physical crash testing is not considered in this paper. Types of questions used in the research can be categorised as quantitative and qualitative.

- Here is an example of a quantitative question:

- "In your opinion, what would be the cost drivers involved in PT and their weight?"

- Here is an example of a qualitative question : 
- "What are the examples of successful application of VT replacing the PT?"

An IDEF0 process map of the physical test domains was produced. The process mapping exercise enabled understanding of the target domain and the identification of cost elements and their associated cost drivers. This resulted in a Cost Breakdown structure shown in Figure 1.

\section{Physical Crash Testing Results}

The process of physical crash testing has evolved dramatically since the first official test took place in 1969. It remains the primary measure of vehicle crashworthiness, and indeed the only compulsory method accounted for in official legislation. In order to maintain consistency, legislation and benchmarking abilities, a crash is carried out under specific impact configurations, such as speed, type and positioning of the dummy passengers, amount of sensors and external recording equipment. Those can be defined by the customer in the original specification documents.

A standard crash test takes in order of a week to complete, the five primary stages. Once the prototype arrives at the testing house, approximately 3-4 days are spent preparing the crash scenario, including setting up the rig, monitoring equipment, instrumentation, positioning the vehicle and barrier, and setting up the dummy. This is highly labour intensive.

Running the impact test typically takes place during one full day, including the last minute preparations and final dummy placement, the crash itself, and the immediate post-crash assessment.

After the test, the analysis of the crash data typically takes 2-3 days, wherein the data collected is processed, analysed and translated into a usable form for the client.

The Work Breakdown Structure (WBS) in Figure 3 details the physical crash activities only. This aids in identifying the key areas of work throughout the process.

\section{Cost Analysis of Physical Crash Testing}

Directed towards a more qualitative, dynamical analysis, a cost graph analysis was created to map the variation, magnitude and evolution of key cost elements.

These cost graph analyses are based on the cost data gathered, interviews compiled and process maps formulated and was carried out via two different dimensions:

- First: mapping the major cost drivers from the test house point of view (labour, instrumentation costs), and plots the development of these over the five key stages of a crash test (Figure 2), 
- Second: taking the major cost driving customer specifications and monitoring their variation within a crash test over the key stages of a vehicle product development process (Figure 4).

\subsection{First analysis}

Most of these cost components (aside from those which vary according to customer specifications, such as cameras and accelerometers) are presented to the manufacturer as a fixed overhead cost. In reality, however, the distribution of these costs across the various stages is not uniform, in fact different costs accumulate at different stages.

The length of each stage is not uniform, and largely depends on the specific test in question. Although the running of the test itself is largely more labour intensive than the preparation stage, it takes place over a shorter period of time, and thus the overall cost accumulation of labour is generally larger in the preparation stage.

Dummies are expensive kit to acquire and maintain. In addition to purchasing costs, there are the post-crash maintenance costs (certify, position, set up and rework the dummy) in addition to any additional instrumentation forming the largest costs associated with the dummy. Naturally, the highest stage of dummy costs accumulates within the running of the impact test itself, although costs arise again during the equipment reworking stage.

The price of still and high-speed photography and data channels is judged via both the number and technical specification of the equipment itself. This cost component does vary greatly depending on customer specifications. This factor understandably peaks in the running of the impact test itself.

'Consumables and overheads' are also another major cost component in the running of a crash test. This category contains all indirect costs, including the cost of the facility and equipment, administration and power. This is typically charged as a fixed percentage of the crash cost, based on standard overhead calculation procedures, considering factors such as depreciation of facilities.

A large selection of computational hardware and software is in use throughout the testing procedure, both for monitoring and analysing the crash. It peaks in the analysis of results section, where the raw crash data is processed.

\subsection{Second analysis}

The cost of the prototype is by far the dominant cost driver throughout the development stages, proving a huge expense particularly in the initial prototype testing stage. Here the model has been crafted on an individual and developmental basis. The prototype cost drops dramatically at the final model certification stage, where the prototype for testing is simply a car directly off the production line.

The number of data channels is low during concept and component testing. The figure peaks and plateaus within the intermediate testing stages. Within the final testing stage there are still a considerable number of data channels to pass the legislative testing, but less than in the developmental stages.

The price of still photography costs are judged via the average number of exposures produced at each stage. The price of high-speed photography is judged 
via both the number and technical specification of the high-speed recording equipment. Both factors slightly drop between the initial prototype phase and the complete model testing phase. Monitoring increases for the final stage inline with the legislation requirements in assessing the car's crash performance.

When discussing the number of reference targets, this analysis usually meets its maximum within the initial prototype development stage, as this is the first stage where a vehicle is tested in its entirety; and thus the stage where most information is gleaned concerning chassis behaviour under impact.

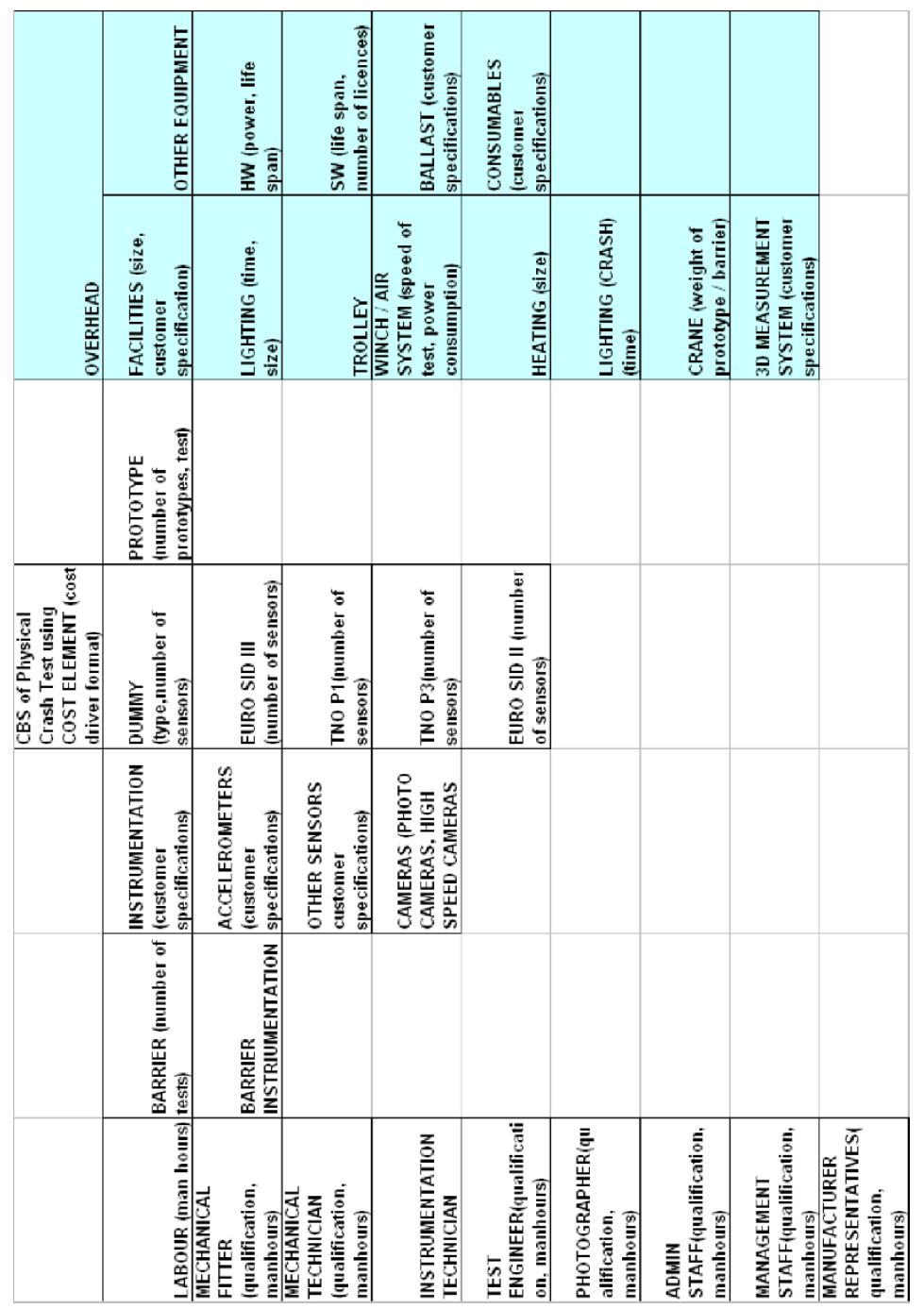

Figure 1. Cost Breakdown Structure derived from I-DEF0 process maps 


\section{Validation}

Validation of the physical crash test results in this paper was performed by (1) Expert A from the automotive sector with working experience as Chief Executive Officer and academia, (2) Expert B with 10 years crash testing experience, (3) Expert $\mathrm{C}$ being a Cost engineer with experience in automotive sector for about 30 years and (4) an automotive related company. The results were altered in parts to reflect the results of the validation process.

\section{A graph depicting the evolution of cost driving customer specifications throughout the key vehicle developmental stages}

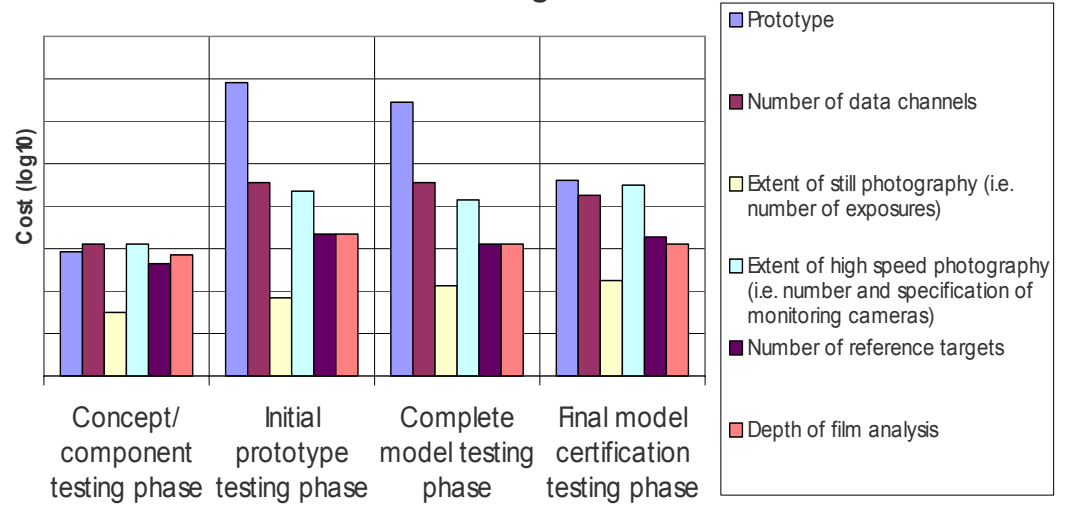

Figure 2. Evolution of principal cost drivers throughout the key stages of a full scale crash test

\section{Discussion}

Physical crash testing is the only established method of carrying out full-scale vehicle crash testing currently accounted for within worldwide legislation. All manufacturers need to complete specific physical legislative scenarios in order to place their vehicle for commercial sale. It allows one to monitor the actual (as opposed to theoretical) behaviour of the car under impact, allowing unpredicted faults to be noticed.

Physical crash testing is an extreme expense for manufacturers, especially when taking into account the large variety and iterations of test required throughout the vehicle design process. A multitude of expensive prototypes need to be produced, and can only be crashed one time. Each test can only be performed under a specific, exact configuration, without being able to give any valid data concerning any slight or major scenario variations. 


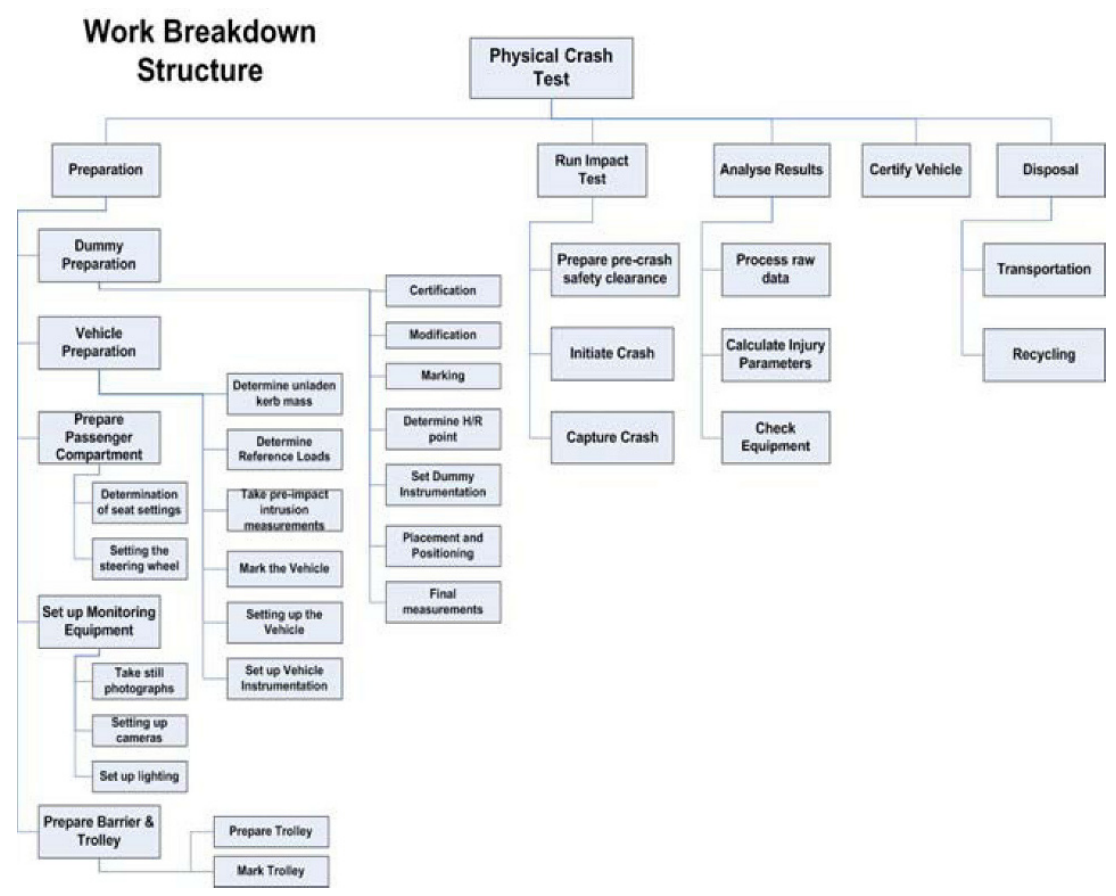

Figure 3. Work Breakdown Structure of Physical Crash Testing

Dummies utilised in standard crash tests do not by any means cover an allencompassing range of body types, shapes and seating positions, when in reality any variety of these factors could have large implications to the extent of occupant injury.

Variations in both the crash scenario and dummy characteristics could be easily altered for a virtual test for multiple iterations, where as for a physical test a whole new test would need to be set up, adding extra expense and time to the vehicle certification process.

\section{Conclusion}

This research has considered costs of front and side impact in Physical Crash Testing. The cost of physical crash test is influenced by some significant cost drivers. Depending on the stage in the new product development process, a prototype car to be crashed can be anything from ten thousand pounds to one million pounds. The first or early prototypes being the most expensive. Other major cost elements are: labour, crash barrier, instrumentation, crash dummies, and overheads of facility and other equipment. A crash dummy can be the order of a hundred thousand pounds and then must be maintained and re-worked. A crash test can take the order of a week for preparation, a day for the crash test and two to 
three days to analyses the results. There were eight types of labour involved during the full cycle of a crash test. Most of the labout was required during preparation. The more information that was required from a crash test the more instrumentation was used. Knowing the cost at the design stage will support concurrent engineering of a vehicle through trade off analysis among the cost drivers.

\section{A graph depicting the evolution of principal cost drivers throughout the key stages of a full scale crash test}

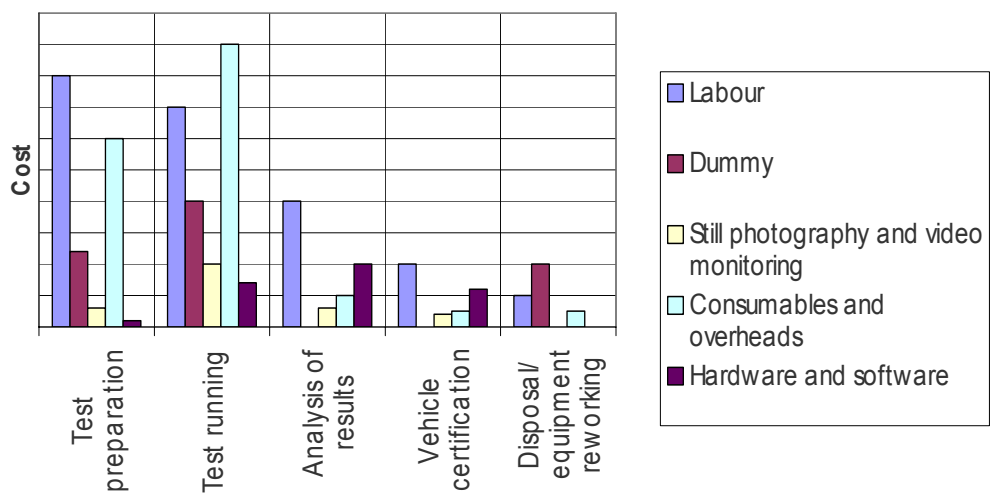

Figure 4. Evolution of cost driving customer specifications throughout the key vehicle development stages

Due to the significant cost of the physical crash testing the use of more strategic virtual crash testing is a potential solution to cost reduction.

\section{Acknowledgements}

This works acknowledges the funding from the Integrated Framework 6 Project on Advanced Protection Systems (Aprosys, www.aprosys.com)). The authors are also grateful to the members of Decision Engineering Centre for their contribution to the research. 


\section{References}

[1] UNITED NATION ECONOMIC COMMISSION FOR EUROPEhttp://www.unece.org/, first accessed 15/02/2008.

[2] GRANT, I.C., BAGULEY, P., AND ROY, R., Development of a Cost Engineering Knowledge Audit Tool, the $4^{\text {th }}$ International Conference on Digital Enterprise Technology (DET 07). Bath University, 19-21 September, 2007.

[3] ROY, R., KElVESJO, S., FORSBERG, S., AND RUSH, C. Quantitative and Qualitative Cost Estimating for Engineering Design. Journal of Engineering Design, Vol. 12, No. 2, pp. 147-162, 2001. 